\title{
A Systematic Analysis of Adolescents' Physical Activity Level and Sedentary Behavior
}

\section{Salem Alshammari}

Kuwait University

Heyam Reda Boushehry ( $\nabla$ mobarak1955@msn.com )

https://orcid.org/0000-0002-2348-789X

\section{Sultan Mohammed Alsahli}

Kuwait university

\section{Research}

Keywords: Young People, Physical Activity Level, Watching Television, Sedentary Behaviors

Posted Date: May 20th, 2020

DOl: https://doi.org/10.21203/rs.3.rs-28358/v1

License: (1) This work is licensed under a Creative Commons Attribution 4.0 International License. Read Full License 


\section{Abstract}

Physical activity (PA) promotion and sedentary behavior (SB) reduction are needed to address the increasing rates of noncommunicable diseases (World Health Organization. Noncommunicable diseases, 2018). In the last two decades, there has been an increase in the incidence of both overweight young people and diabetes. Many countries have been looking for solutions to help young people achieve wellbeing (Centers for Disease Control and Prevention, 2011). However, few studies have been conducted to examine PA levels among adolescents, which leaves gaps to be filled regarding the understanding of overall health in adolescents. The purpose of this study was to examine the extent to which adolescents engage in regular PA as opposed to sedentary activities, such as watching television and using the internet, after controlling for sex and age. Finally, this study helped address how adolescents spend their time engaging in PA. The data were obtained from the National Youth Risk Behavior Survey (NYRB-S) 2007 by the Centers for Disease Control (http://www.cdc.gov/HealthyYouth/yrbs/data/). The participants in this study consisted of (14041) adolescents ranging in age from 12 to 18 years old. The NYRB-S was an instrument used to assess risk factors that affect adolescents. We concluded that there were significant overall effects of daily time watching television and age on PA level. Subjects who spent 4 to 14 hours daily watching television had a significantly higher mean level of PA than subjects who watched television for 0 to 4 hours daily. The analysis also showed that the seven age groups differed significantly. There were significant correlations between time spent engaging in SB, age and PA levels. An increase in television viewing was related to a decrease in PA, and subjects between the ages of 13 and 16 tended to watch television more frequently.

\section{Introduction}

In the last two decades, there has been an increase in the incidence of both overweight young people and diabetes. Many countries have been looking for solutions to help young people achieve well-being (Centers for Disease Control and Prevention, 2011; World Health Organization. Noncommunicable diseases, 2018). For example, two countries, the United States and Kuwait, have seen dramatic increases in the rates of obesity and diabetes among young people (Al-Isa, Campbell, \& Desapriys, 2010; Centers for Disease Control and Prevention, 2011; World Health Organization. Noncommunicable diseases, 2018). Previous studies have shown that physical inactivity and the prevalence of sedentary lifestyles are leading contributors to this epidemic. Al-Isa et al. (2010) and the Centers for Disease Control and Prevention (2011) recommended increasing the level of physical activity (PA), which plays a vital role in reducing the risk of contracting these diseases. PA promotion and sedentary behavior (SB) reduction are needed to address the increasing rates of noncommunicable diseases (World Health Organization. Noncommunicable diseases, 2018).

However, few studies have been conducted to examine PA levels among adolescents, which leaves gaps to be filled regarding the overall health status of adolescents. Recently, SB has become an epidemic in many countries, but little is known about how adolescents choose to spend their time or whether or not they are physically active. For instance, there was only one study published on SB among Kuwaiti 
adolescents (Al-Haifi, Al-Fayez, Al-Athari, Al-Ajmi, Allafi, Al-Hazzaa, \& Musaiger, 2013). The results of this study revealed that, "With regard to sedentary behavior, time spent watching television and time spent on the computer were not significantly related to BMI in boys or girls" and needs to be examined further (p. 9). The lack of information demands an investigation on how PA affects a substantial portion of the adolescent population. This study examined the extent to which adolescents engage in regular PA as opposed to sedentary activities, such as watching television and using the internet, after controlling for sex and age. Finally, this study helped address how adolescents spend their time engaging in PA.

\section{Literature Review}

The U.S. Department of Health and Human Services discusses the importance of performing regular PA among adolescents. They found a direct correlation between regular PA and health among adolescents. The National Association for Sports and Physical Education \& the American Heart Association (2010) have provided an excellent example of the correlation between regular PA and health, claiming that "adolescents who are physically active have vigorous cardiopulmonary and respiratory systems: strong hearts and lungs. They have less body fat. And they have strong bones and muscles" (p. 3). Recently, there has been increasing interest in adolescent health and health care services to determine how to improve overall well-being within that demographic group (Al-Qallaf Al-Otaibi, \& Heyam, 2012).

In many countries there are many barriers to increasing the rate of PA. One of these problems is the current level of physical inactivity, which is partly due to insufficient participation in PA during leisure time. According to the American Heart Association and the American Stroke Association's Statistical Fact Sheet (2013), 13.8\% of adolescents in the United States "were inactive during the previous 7 days, as indicated by their response that they did not participate in 60 minutes (as recommended in Healthy People, 2010) of any kind of PA that increased their heart rate and made them breathe hard on any 1 of the previous 7 days". In the last decade, many researchers and organizations (e.g., the National Association for Sport and Physical Education, 2010; the American Heart Association, 2010; Al-Isa, Campbell, \& Desapriys, 2010) have studied how young people spend their time engaging in PA and the benefits of being physically active. There is no existing formal data that describes how much PA adolescents engage in.

Recently, more research has been conducted that has hypothesized that SB correlates with a lack of PA or a single behavior. SB is defined as activity that does not increase energy exertion significantly above the resting level and includes activities such as sleeping, sitting, using the internet, and watching television and other forms of screen-based entertainment (Pate, O'Neill, \& Lobelo, 2008). A high level of SB negatively impacts youths' health, independent of other factors such as body weight, diet, and PA.

According to several studies, television, tablet use, smartphone use, and screen viewing in general presents the main means of engaging in SB (Regan \& Heary, 2013; Salmon, Tremblay, Marshall, \& Hume, 2011; O'Neill, \& Lobelo, 2008). Recently, the time spent watching television and using tablets among adolescents has dramatically increased. Nelson, Neumark-Stzainer, Hannan, and Sirard (2006) found that 
the estimated time spent watching television among adolescents is 2.5-3 hours per day, and an additional 1.5-2 hours is spent using computers and tablet sin the U.S. and Kuwait. This investigation shows that adolescents spend at least five hours a day viewing screens, which accounts for $32-56 \%$ of an adolescent's total sedentary time, as mentioned by Biddle, Gorely, \&Marshall (2009). On the other hand, these results show that adolescents do not follow the recommendation of the American Academy of Pediatrics (2001), which suggests that adolescents limit television and other screen time to no more than 2 hours per day. These studies show that adolescents are prioritizing sedentary activities over physical activities (Biddle, Gorely, \& Marshall, 2009).

The amount of PA and SB among adolescents exhibits gender differences, which were specifically investigated by Vihjalmsson \& Kristjansdottir (2003). This Icelandic study of students in the 6th, 8th, and 10th grades showed that girls enrolled in sports clubs less than boys due to gender differences. Gender differences are also responsible the low level of strenuous activity and high rate of withdrawal from sports clubs among girls. Vihjalmsson \& Kristjansdottir cite the "disadvantages of the female gender" as a factor involved in their higher level of physical inactivity, as opposed to males. They claimed that "the structure and/or culture of organized sport favors boys and men" (P. 2).

Age is also a factor in PA level and SB. De Bourdeaudhuij, Philippaerts, Crombez, Matton, Wijndaele, Balduck, and Lefevre (2005) addressed levels of PA among age groups by dividing adolescents into three groups, based on age and activity level: precontemplation, contemplation, and preparation. They found that "the level of PA during adolescence was higher than during adulthood. There may have been few adolescents in the precontemplation and contemplation stages, resulting in low statistical power" (P. 2).

While PA is immensely beneficial for adolescents, SB is more prevalent in that demographic, particularly in girls compared to boys. Adolescents do tend to be more active than adults, but the levels of PA in adolescents are difficult to measure because "it is not known whether adolescents are able to adequately evaluate their own level of physical activity" (De Bourdeaudhuij, I., et. al., 2005, P. 2).

The purpose of this study, therefore, will be to examine the amount of SB, for example, "watching television and using the internet", among adolescents and how time spent in SB affects PA levels. The study will control for age and gender to determine what effects those variables have on levels of PA and engagement in SB.

\section{Research Question}

The primary focus of this study will be to determine the levels of PA and SB among adolescents. This study intends to determine what effect the number of hours that students spend engaging in SBs on a typical day have on adolescents' PA level after controlling for sex and age. See Fig. 1

\section{Path Diagram}




\section{Four Hypotheses}

1)

After controlling for sex and age, students who spend four or more hours engaging in SBs on a typical day are more likely to be overweight than are students who spend less than four hours engaging in SBs on a typical day (Crosstabs).

2)

After controlling for sex and age, students who spend four or more hours engaging in SBs on a typical day have a lower level of PA than students who spend less than four hours engaging in SBs on a typical day (ANOVA).

3)

After controlling for sex and age, the number of hours that a student spent engaging in SBs on a typical day is negatively related to adolescents' PA level (Regression).

4)

After controlling for sex and age, the more time that students spend engaging in SBs on a typical day, the more likely it is that they will be less physically active (Logistic Regression).

\section{Methods}

\section{Sample and Data Source}

The data were obtained from the National Youth Risk Behavior Survey (NYRB-S) 2007 by the Centers for Disease Control (http://www.cdc.gov/HealthyYouth/yrbs/data/). The participants in this study consisted of (14041) adolescents ranging in age from 12 to 18 years old. The NYRB-S is an instrument used to assess risk factors that affect adolescents.

The independent variables included the adolescents' age and gender. "Age" had seven categories arranged numerically with " 1 " indicating " 12 years or younger" and " 7 " indicating " 18 years or older". "Gender" was divided into two categories labeled numerically, with "1" indicating female and "2" indicating male. The first dependent variable was SB, which was labeled "TVhour". The variable "TVhour" had seven categories identified by letters: "A. I do not watch TV on an average school day", "B. Less than 1 hour per day", "C. 1 hour per day", "D. 2 hours per day”, "E. 3 hours per day", "F. 4 hours per day" and "G. 5 or more hours per day". The second dependent variable was level of PA, which was assessed by two factors: "Vig7D", the number of days the adolescents engaged in vigorous PA within the last seven days, and "Mod7D", the number of days the adolescents engaged in moderate PA within the last seven days. Both "Vig7D" and "Mod7D" had seven categories indicating the days of the week. All variables were included in the SPSS data set.

\section{Results}

Basic descriptive statistics to analyze adolescents' SB can be seen in Table 1. As Table 1 shows, there were approximately equal percentages of boys and girls in the sample and approximately equal numbers 
of participants from the 9 th, 10 th, 11 th, and 12th grades.

Table 1

Descriptive Statistics for Physical

Activity Study Variables

\begin{tabular}{|lll|}
\hline Characteristic & $M$ & $S D$ \\
\hline Height $(\mathrm{m})$ & 1.69 & 0.10 \\
\hline Weight $(\mathrm{kg})$ & 68.55 & 16.99 \\
\hline & $n$ & $\%$ \\
\hline GENDER & & \\
\hline BOYS & 6,992 & $49.8 \%$ \\
\hline GIRLS & 7,036 & $50.1 \%$ \\
\hline GRADE & & \\
\hline 9TH GRADE & 3,467 & $24.7 \%$ \\
\hline 10TH GRADE & 3,482 & $24.8 \%$ \\
\hline 11TH GRADE & 3,480 & $24.8 \%$ \\
\hline 12TH GRADE & 3,529 & $25.1 \%$ \\
\hline
\end{tabular}

For the first hypotheses, the Crosstab method was used, and the results can be seen in Table 2. Table 2 illustrates the results of a chi square analysis of the relationship between two categories of body mass index (BMI) and two categories of hours of SB, controlling for gender. For both boys and girls, there was no significant relationship between the two variables.

Table 2

Characteristics (\%) of Participants: BMI by Sex and Sedentary Behavior $(n=12,844)$

\begin{tabular}{|llllll|}
\hline \multicolumn{1}{|l}{ Characteristic } & BMI less than 25 & BMI 25 or greater & $\mathrm{X}^{2}$ & $\mathrm{df}$ & $\mathrm{p}$ \\
\hline Boys & $n=4269$ & $n=2161$ & 0.00 & 1 & $\mathrm{p}>.05$ \\
\hline Less than 4 hours sedentary & 66.40 & 33.60 & & & \\
\hline 4 + hours sedentary & 66.40 & 33.60 & & & \\
\hline Girls & $n=4676$ & $n=1738$ & 1.81 & 1 & $\mathrm{p}>.05$ \\
\hline Less than 4 hours sedentary & 75.00 & 25.00 & & & \\
\hline 4 + hours sedentary & 72.60 & 27.40 & & & \\
\hline
\end{tabular}


For the second hypotheses, the analysis of variance (ANOVA) method was used, and the results can be seen in Table 3. As shown in Table 3, there was a significant overall effect of daily time watching television and age on PA level $(F(1,7)=15.89, p<.001)$. Subjects who spent 4 to 14 hours daily watching television had a significantly higher mean level of PA than subjects who watched television 0 to 4 hours daily $(F(1,6)=8.26, p<.005)$. The analysis also showed that PA differed significantly among the seven age groups $(F(6,6)=16.54, p<.001)$.

Table 3

Analysis of Variance for Physical Activity

\begin{tabular}{|llllllll|}
\hline Source & M & SE & n & df & F & $p$ \\
\hline Source: Reduced Model & & & & 7 & 15.89 & $\mathrm{p}<.001$ \\
\hline Time Per Day Spent Watching Television & & & & 1 & 8.26 & $\mathrm{p}<.005$ \\
\hline $0-4$ Hours & 5.78 & 0.28 & 1097 & & & \\
\hline $4-14$ Hours & 6.15 & 0.28 & 11242 & & & \\
\hline Age & & & & 6 & 16.54 & $\mathrm{p}<.001$ \\
\hline 12 years or younger & 4.64 & 0.90 & 20 & & & \\
\hline 13 years & 7.01 & 1.53 & 7 & & & \\
\hline 14 years & 6.42 & 0.13 & 1154 & & & \\
\hline 15 years & 6.45 & 0.09 & 2807 & & & \\
\hline 16 years & 6.06 & 0.09 & 3180 & & & \\
\hline 17 years & 5.68 & 0.08 & 3194 & & & \\
\hline 18 years or older & 5.51 & 0.10 & 1977 & & \\
\hline Within-group error & & & & & & \\
\hline Note: Values enclosed in parentheses represent mean square errors. & & & \\
\hline eta ${ }^{2}=.009$ for main effects $(p<.001)$ & & & & & \\
\hline
\end{tabular}

For the third hypotheses, the regression method was used, and the results can be seen in Table 4. As shown in Table 4, SB, sex, and age were all significant predictors of PA. There was a significant negative relationship between SB and PA. The significant negative relationship between gender and PA, with boys as the reference group, indicates that boys tended to have a higher level of PA than girls. The significant negative relationship between age and PA indicates that older subjects tended to have a lower level of activity than younger subjects. 
Table 4

Summary of Regression Analysis for Variables Predicting

Physical Activity Level $(\mathrm{N}=14,041)$

\begin{tabular}{|lccll|}
\hline Variable & $B$ & $S E B$ & $\beta$ & $p$ \\
\hline Main Effects: & & & & \\
\hline Constant & 9.01 & 0.17 & & $p<.001$ \\
Sedentary Behavior & -0.12 & 0.02 & -0.07 & $p<.001$ \\
Gender & & & & \\
Girls & -1.57 & 0.72 & -0.19 & $p<.001$ \\
Boys (Reference) & & & & \\
Age & -0.31 & 0.03 & -0.19 & $p<.001$ \\
\hline Note: $\mathrm{R}^{2}=.046(p<.001)$ & & & & \\
\hline
\end{tabular}

For the fourth hypotheses, the logistic regression method was used, and the results can be seen in Table 5. Table 5 shows the results of a logistic regression predicting PA (in two levels) based on dichotomized SB. The significant negative coefficient and the odds ratio less than 1.00 for SB indicate that subjects who engaged in 4 to 10 hours of SB were less likely to have a high level of PA compared to the likelihood of subjects who engaged in 0 to 3 hours of SB.

Table 5

Summary of Logistic Regression Analysis Predicting Physical Activity Level $(N=14,041)$

\begin{tabular}{|c|c|c|c|c|c|c|c|c|}
\hline \multirow[b]{2}{*}{ Variable } & \multirow[b]{2}{*}{$b$} & \multirow[b]{2}{*}{$S E$} & \multirow[b]{2}{*}{$\begin{array}{l}\text { Odds } \\
\text { ratio }\end{array}$} & \multicolumn{2}{|c|}{$\begin{array}{l}95 \% \text { Confidence } \\
\text { Interval }\end{array}$} & \multirow[b]{2}{*}{$\begin{array}{l}\text { Wald } \\
\text { statistic }\end{array}$} & \multirow[b]{2}{*}{ df } & \multirow[b]{2}{*}{$\mathrm{p}$} \\
\hline & & & & Lower & Upper & & & \\
\hline \multicolumn{9}{|l|}{ Main Effects: } \\
\hline Constant & 0.227 & 0.056 & 1.254 & & & 16.499 & 1 & $\begin{array}{l}\mathrm{p} \\
<.001\end{array}$ \\
\hline \multicolumn{9}{|l|}{ Sedentary Behavior } \\
\hline $\begin{array}{l}4 \text { to } 10 \text { hours of } \\
\text { sedentary behavior }\end{array}$ & -0.239 & 0.036 & 0.787 & 0.733 & 0.845 & 43.776 & 1 & $\begin{array}{l}\mathrm{p} \\
<.001\end{array}$ \\
\hline $\begin{array}{l}0 \text { to } 3 \text { hours of sedentary } \\
\text { behavior }\end{array}$ & \multicolumn{8}{|c|}{ (reference) } \\
\hline Note: Model Chi Square $=$ & $873, d t$ & $1(p<.0$ & 1); - $2 \mathrm{~L}$ & Likelir & $=170$ & 981, Nag & rke & $=.005$ \\
\hline
\end{tabular}




\section{Conclusion}

All the results above addressed the research question and the primary focus, which was to determine the amount of PA and SB among adolescents. This study explored the effect of the number of hours that students spend engaging in SBs on a typical day on adolescents' PA level after controlling for gender and age. We hypothesized that after controlling for gender and age, students who spend four or more hours engaging in SBs on a typical day are more likely to be overweight than students who spend less than four hours engaging in SBs on a typical day.

However, we concluded that there was a significant overall effect of daily time spent watching television and age on PA level. Subjects who spent 4 to 14 hours daily watching television had a significantly higher mean level of PA than subjects who watched television for 0 to 4 hours daily. The analysis also showed that the seven age groups differed significantly. There were significant correlations between time spent engaging in SB, age and PA levels. An increase in television-viewing time was related to a decrease in PA, and subjects between the ages of 13 and 16 years tend to watch television more frequently.

\section{Declarations}

\section{Ethics}

The data were obtained from the National Youth Risk Behavior Survey (NYRB-S) 2007 by the Centers for Disease Control (http://www.cdc.gov/HealthyYouth/yrbs/data/).

\section{Consent for publication}

“Not applicable”

\section{Availability of data and material}

The data were obtained from the National Youth Risk Behavior Survey (NYRB-S) 2007 by the Centers for Disease Control (http://www.cdc.gov/HealthyYouth/yrbs/data/).

\section{Competing interest}

On behalf of all authors "Salem A;Sammari, Sultan Alsahali", I am Dr. Heyam Boushehry, the corresponding author of the present study, I declare that this paper did not receive any funds from any institution. It was self-funded by the authors.

\section{Funding}

The present research is self-funded by authors.

\section{Authors contribution}


Al-Shammari Salem, Boushehry Heyam, Alsahli Sultan.

A.S. B.H., \& A.S; Designed and performed the study, analyzed data and co-wrote the paper. B.H., A.S; Supervised the research. A.S; finalize the study, review, \& edit. A.S. B.H., \& A.S; agree with Final approval of the version to be published

\section{Acknowledgments}

The research for this paper was financially supported by the authors "Salem Al-Sammari, Heyam Boushehry, \& Sultan Alsahli. In developing the ideas presented here, I have received helpful input from the National Youth Risk Behavior Survey (NYRB-S) 2007 by the Centers for Disease Control. We would also like to show our gratitude to the (the National Youth Risk Behavior Survey (NYRB-S) 2007 by the Centers for Disease Control) for sharing their data.

\section{References}

Al-Haifi, A., Al-Fayez, M., Al-Athari, B., Al-Ajmi, F., Allafi, A., Al-Hazzaa, H., \& Musaiger, A. (2013). Relative contribution of physical activity, sedentary behaviors, and dietary habits to the prevalence of obesity among Kuwaiti adolescents. Food And Nutrition Bulletin, 34(1), 6-13.

Al-Isa, A., Campbell, J., \& Desapriya, E. (2010). Factors associated with overweight and obesity among Kuwaiti elementary male school children aged 6-10 years. International Journal of Pediatrics, 2010, Article ID 459261, 1- 6. doi:10.1155/2010/459261.

Al-Isa, A., Campbell, J., Desapriya, E., \& Wijesinghe, N. (2011). Social and Health Factors Associated with Physical Activity among Kuwaiti College Students. Journal of Obesity, 1-6. doi:10.1155/2011/512363

Al-Qallaf, B. R., NMB Al-Otaibi, .., \& Heyam. (2012). Perception of Adolescents Towards Health Related Issues in Secondary Schools, Kuwait. European Journal Of General Medicine, 9(3), 162-169.

American Academy of Pediatrics (2001), Committee on Public Education Children, adolescents, and television Pediatrics, 107, 423-426.

American Heart Association and the American Stroke Association (2013). Clinical Registries. Retrieved from http://www.heart.org/idc/groups/heart-

public/@wcm/@adv/documents/downloadable/ucm_432451.pdf

Biddle, S.J., Gorley, T. and Marshall, S.J. (2009). The prevalence of sedentary behavior and physical activity in leisure time: A study of Scottish adolescents using ecological momentary assessment. U.S. National Library of Medicine. Retrieved from http://www.ncbi.nlm.nih.gov/pubmed/19046984.

Central for Disease Control and Prevent. (2011, March 10). Healthy Youth! Retrieved March 10, 2011, from http://www.cdc.gov/HealthyYouth/physicalactivity/. 
De Bourdeaudhuij, I., Philippaerts, R., Crombez, G., Matton, L., Wijndaele, K., Balduck, A., \& Lefevre, J. (2005). Stages of Change for Physical Activity in a Community Sample of Adolescents. Health Education Research, 20(3), 357-366.

Ding D, Lawson KD, Kolbe-Alexander TL, Finkelstein EA, Katzmarzyk PT, van Mechelen W, Pratt M, Committee LPASE (2016). The economic burden of physical inactivity: a global analysis of major noncommunicable diseases. Lancet. 2016;388(10051):1311-24.

Healthy People.gov. (2010). Find evidence-based information and recommendations related to physical activity. Retrieved March 15, 2011, from http://healthypeople.gov/2020/topicsobjectives2020/ebr.aspx? topicid=33\#recom

National Association for Sport and Physical Education \& American Heart Association. (2010). 2010 Shape of the nation report: Status of physical education in the USA. Reston, VA: National Association for Sport and Physical Education.

Nelson, M.C., D. Neumark-Stzainer, P.J. Hannan, J.R. Sirard, M. (2006). Story Longitudinal and secular trends in physical activity and sedentary behavior during adolescence Pediatrics, 118, pp. e1627-e1634 2006.

Pate RR, O’Neill JR, Lobelo F (2008). The evolving defınition of "sedentary." Exerc Sport Sci Rev 2008;36:173- 8.

Regan, A., \& Heary, C. (2013). Patterns of Sedentary Behaviours in Irish Female Adolescents. Journal Of Adolescence, 36(2), 269-278.

Salmon, J., Tremblay, M. S., Marshall, S. J., \& Hume, C. (2011). Health Risks, Correlates, and Interventions to Reduce Sedentary Behavior in Young People. (Report). American Journal of Preventive Medicine, (2), 197. doi:10.1016/j.amepre.2011.05.001

Vilhjalmsson, R., \& Kristjansdottir, G. (2003). Gender differences in physical activity in older children and adolescents: the central role of organized sport. Social Science \& Medicine, 56(2), 363-374.

World Health Organization. Noncommunicable diseases. (2018) . Retrieved February 2, 2018, from http://www.who.int/mediacentre/factsheets/fs355/en/.

\section{Figures}




\section{Path Diagram}

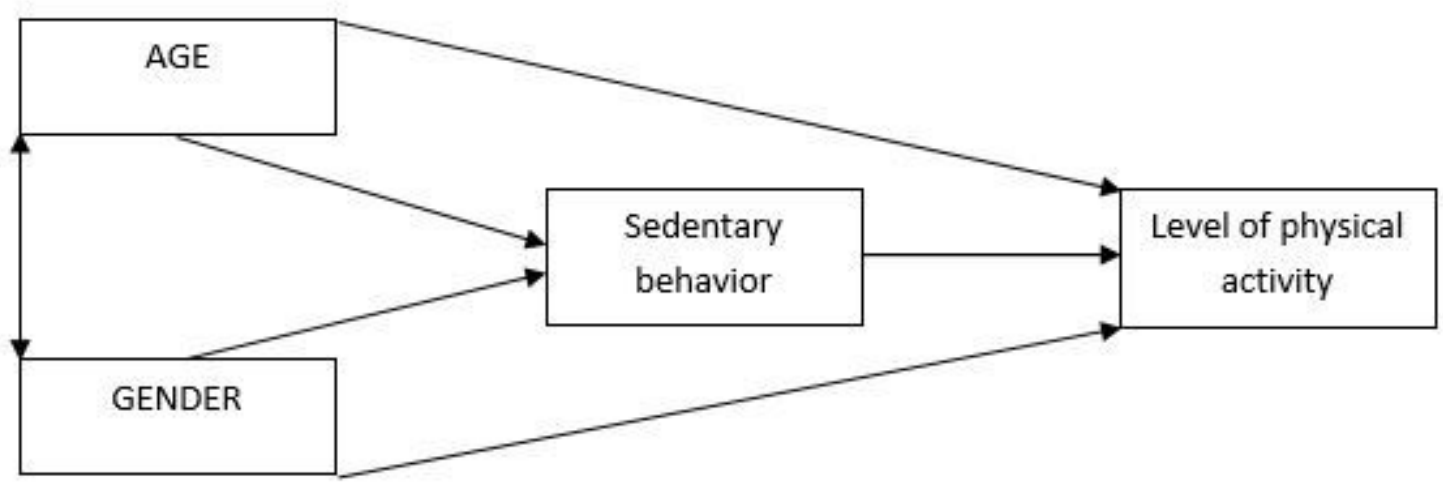

Figure 1

Path Diagram 